\title{
A STUDY ON FOETOMATERNAL OUTCOMES AMONG GESTATIONAL DIABETES MELLITUS PATIENTS IN A TERTIARY CARE HOSPITAL, WESTERN ODISHA
}

\author{
Lalmohan Nayak1, Rabinarayan Dash², Satyanarayan Panigrahi ${ }^{3}$
}

${ }_{1}^{1}$ Associate Professor, Department of Obstetrics and Gynaecology, VSS Institute of Medical Sciences and Research, Burla, Odisha. ${ }^{2}$ Senior Resident, Department of Obstetrics and Gynaecology, VSS Institute of Medical Sciences and Research, Burla, Odisha. ${ }^{3}$ Postgraduate Student, Department of Obstetrics and Gynaecology, VSS Institute of Medical Sciences and Research, Burla, Odisha.

\section{ABSTRACT}

\section{BACKGROUND}

Gestational diabetes mellitus (GDM) is a common metabolic disorder in pregnancy. The incidence of GDM increases in older and more obese pregnant women. GDM increases the risk of certain pregnancy complications like pregnancy-induced hypertension and adverse perinatal outcome.

Aims and Objectives-

1. To assess the foetomaternal outcome in pregnant women with gestational diabetes mellitus.

2. To find out the relationship of BMI in pregnant women with GDM and its foetomaternal outcome.

\section{MATERIALS AND METHODS}

It was a prospective observational study conducted in the Department of Obstetrics and Gynaecology, VSSIMSAR, Burla, Sambalpur, Odisha with a total sample size of 100.

\section{RESULTS}

Maternal complications like UTI, polyhydramnios, IUGR and vaginal candidiasis were proportionately more in GDM group than in Non-GDM group. Out of all neonatal complications, only hyperbilirubinaemia cases were found to be statistically significantly associated with GDM with ( $\mathrm{p}$ value $<0.05)$. The mean BMI of total patients found out to be $\left(26.40 \pm 4.94 \mathrm{~kg} / \mathrm{m}^{2}\right)$. Mean BMI was higher in women with GDM $\left(29.81 \pm 3.76 \mathrm{~kg} / \mathrm{m}^{2}\right)$ than Non-GDM $\left(23.00 \pm 3.39 \mathrm{~kg} / \mathrm{m}^{2}\right)$. Only vaginal candidiasis is found to be statistically significantly associated with BMI ( $p$ value $<0.05$ ).

\section{CONCLUSION}

Many maternal and foetal complications are significantly seen more among GDM population compared to Non-GDM group. Early universal screening is essential.

\section{KEYWORDS}

GDM, BMI, Maternal Conditions.

HOW TO CITE THIS ARTICLE: Nayak L, Dash R, Panigrahi S. A study on foetomaternal outcomes among gestational diabetes mellitus patients in a tertiary care hospital, Western Odisha. J. Evolution Med. Dent. Sci. 2018;7(17):2149-2152, DOI: $10.14260 /$ jemds/2018/481

\section{BACKGROUND}

Gestational diabetes mellitus (GDM) is a common metabolic disorder in pregnancy and is defined as "any degree of glucose intolerance with onset or first recognition during pregnancy with or without remission after the end of pregnancy."(1) It is estimated that 1 out of 200 pregnancies is complicated by diabetes mellitus and additionally 5 in every 200 pregnant women will develop gestational diabetes mellitus (GDM).(2) GDM is diagnosed in approximately $3-7 \%$ of pregnancies. $(2,3,4)$ The incidence of GDM increases in older and more obese pregnant women. GDM increases the risk of certain pregnancy complications like pregnancy-induced hypertension and adverse perinatal outcome. It carries the risk of later development of type 2 diabetes mellitus (DM) in $75 \%$ of cases. $(1,3,4,5,6,6,7)$

'Financial or Other Competing Interest': None.

Submission 03-03-2018, Peer Review 06-04-2018,

Acceptance 12-04-2018, Published 23-04-2018.

Corresponding Author:

Dr. Rabinarayan Dash,

Quarter No. D2,

Doctors Colony, Burla,

Sambalpur-768017, Odisha.

E-mail: dr.rabinarayandash05@gmail.com

DOI: $10.14260 /$ jemds/2018/481
Offspring of women with GDM are at increased risk of obesity, glucose intolerance and diabetes in late adolescence and young adulthood.(8) Women diagnosed with GDM are at increased risk for a variety of pregnancy complications including gestational hypertensive disorders, foetal macrosomia, shoulder dystocia and caesarean delivery. ${ }^{(9)}$ So this study was conducted with the objectives: 1 ) To assess the foetomaternal outcome in pregnant women with gestational diabetes mellitus; 2) To find out the relationship of BMI in pregnant women with GDM and its foetomaternal outcome.

\section{MATERIALS AND METHODS}

It was a prospective observational study conducted in the Department of Obstetrics and Gynaecology, VSSIMSAR, Burla, Sambalpur, Odisha.

100 cases were taken, out of which 50 were cases with GDM and same number of cases without GDM were taken as control. The cases were taken from those who attended the antenatal clinics or were admitted to the same department. All the cases had antenatal check-up in the antenatal period and were advised for delivery and postpartum check-up. A detailed clinical assessment of the patient was performed in the OPD. Routine investigations were done during antenatal visits after informing them about the present study and consent was also taken. 
The pregnant women irrespective of trimesters, fasting status or timing of previous meal were given $75 \mathrm{~g}$ glucose load orally and the blood sugar levels were measured after 2 hours. The women underwent 2-hour PGBS test in the later weeks of pregnancy, if they had normal glucose tolerance in the first visit. Those women with 2-hour PGBS level $\geq 140$ $\mathrm{mg} / \mathrm{dL}$ were diagnosed as GDM and were taken as cases and those having $2 \mathrm{hrs}$. PGBS $<140 \mathrm{mg} / \mathrm{dL}$ were taken as controls and were followed up to compare the foetomaternal outcome.

\section{Inclusion Criteria}

1. Pregnant women attending antenatal clinic and having GDM and expected to deliver at VSSIMSAR, Burla, were taken as cases.

2. Pregnant women attending antenatal clinic and not having GDM were taken as controls.

3. Pregnant women of any parity.

\section{Exclusion Criteria}

1. Patients with known type 1 or type 2 Diabetes mellitus.

2. Pregnant women having chronic diseases/ cardiac/ hepatic/ respiratory diseases.

3. Taking drugs that alter glucose metabolism.

Statistical analysis was done in SPSS Version 16. Percentage and chi-square were used to find the relationship of the foetomaternal outcome. Ethical clearance was taken from the institutional authority.

\section{RESULTS}

Majority of GDM women were in the age group of $\geq 25$ years (76\%). $8 \%$ of GDM women belonged to urban areas, whereas $20 \%$ of GDM women belonged to rural areas. Most (76\%) of Non-GDM women belonged to rural areas and (24\%) belonged to urban areas. Majority of patients belonged to lower socioeconomic status. Among GDM group (60\%) belonged to middle class, whereas in Non-GDM (70\%) belonged to lower class.

(56\%) GDM cases had family history of DM. $60 \%$ of the patients with GDM were G2-G4 parity. On the other hand, $68 \%$ of subjects in the Non-GDM group were primigravidae.

\begin{tabular}{|c|c|c|c|c|c|c|c|}
\hline \multirow[b]{2}{*}{$\begin{array}{c}\text { Maternal } \\
\text { Complications }\end{array}$} & \multicolumn{2}{|c|}{ GDM } & \multicolumn{2}{|c|}{ Non-GDM } & \multicolumn{2}{|c|}{ Total } & \multirow[b]{2}{*}{ P-value } \\
\hline & $\begin{array}{l}\text { Nos. } \\
\text { (50) }\end{array}$ & $\%$ & \begin{tabular}{|l|} 
Nos. \\
$(50)$
\end{tabular} & $\%$ & $\begin{array}{l}\text { Nos. } \\
\text { (50) }\end{array}$ & $\%$ & \\
\hline Polyhydramnios & 6 & 12 & 2 & 4 & 8 & 8 & 0.140 \\
\hline UTI & 11 & 22 & 5 & 10 & 16 & 16 & 0.102 \\
\hline Preterm Lab & 6 & 12 & 4 & 8 & 10 & 10 & 0.505 \\
\hline IUGR & 5 & 10 & 2 & 4 & 7 & 7 & 0.240 \\
\hline $\begin{array}{c}\text { Vaginal } \\
\text { Candidiasis }\end{array}$ & 6 & 12 & 3 & 6 & 9 & 9 & 0.295 \\
\hline Nil & 16 & 32 & 34 & 68 & 50 & 50 & 0.000 \\
\hline
\end{tabular}

Table 1 shows that maternal complications like UTI, polyhydramnios, IUGR and vaginal candidiasis were proportionately more in GDM group than in Non-GDM group. Out of $50 \mathrm{GDM}$ patients, 16 were having no complication. UTI occurred in $22 \%$ of GDM patients. In Non-GDM group $10 \%$ of patients had UTI, 68 had no complications in comparison to $32 \%$ of GDM patients which has got statistically high significance with ' $p$ ' value of 0.000 . All other parameters were not statistically significant.

\begin{tabular}{|c|c|c|c|c|c|c|c|}
\hline \multirow[b]{2}{*}{$\begin{array}{c}\text { Neonatal } \\
\text { Complications }\end{array}$} & \multicolumn{2}{|c|}{ GDM } & \multicolumn{2}{|c|}{ Non-GDM } & \multicolumn{2}{|c|}{ Total } & \multirow[b]{2}{*}{$\begin{array}{c}P \\
\text { value }\end{array}$} \\
\hline & \begin{tabular}{|l|} 
Nos. \\
$(45)$
\end{tabular} & $\%$ & $\begin{array}{l}\text { Nos. } \\
(48)\end{array}$ & $\%$ & $\begin{array}{l}\text { Nos. } \\
(93)\end{array}$ & $\%$ & \\
\hline Birth as & 3 & 6.66 & 2 & 4.16 & 5 & 5.37 & \begin{tabular}{|l|}
0.593 \\
\end{tabular} \\
\hline Hypogly & 7 & 5.5 & 2 & .16 & 9 & 9.6 & 063 \\
\hline $\begin{array}{c}\text { Hyper } \\
\text { bilirubinaemia }\end{array}$ & 6 & 13.3 & 1 & 2.08 & 7 & 7.52 & 00 \\
\hline Polycythaemia & 3 & 6.66 & 0 & 0 & 3 & 3.22 & \begin{tabular}{|l|}
0.069 \\
\end{tabular} \\
\hline Hypocal & 3 & 6.66 & 0 & 0 & 3 & 3.22 & 0.069 \\
\hline $\begin{array}{l}\text { Respiratory } \\
\text { Distress }\end{array}$ & 8 & 17.7 & 5 & 10.4 & 13 & 13.9 & 0.30 \\
\hline Nil & 15 & 33.3 & 38 & 79 & 53 & 56.9 & 0.000 \\
\hline & & mnlis & & & & & \\
\hline
\end{tabular}

Table 2 states that Neonatal complications like hyperbilirubinaemia, hypoglycaemia, respiratory distress, polycythaemia and hypocalcaemia are proportionately more in GDM group than in Non-GDM group. 33.3\% of GDM group had no neonatal complications, whereas $79 \%$ of Non-GDM group had no neonatal complications which was statistically highly significant ( $p$ value 0.000 ). $6.66 \%$ of GDM women had birth asphyxia of their babies in comparison to $4.16 \%$ of NonGDM women for the same. Out of all neonatal complications, only hyperbilirubinaemia cases were found to be statistically significantly associated with GDM ( $\mathrm{p}$ value $<0.05$ ).

\begin{tabular}{|c|c|c|c|c|c|c|}
\hline \multirow{2}{*}{$\begin{array}{c}\text { BMI } \\
\left(\mathbf{k g} / \mathbf{m}^{2} \mathbf{)}\right.\end{array}$} & $\begin{array}{c}|c| \\
\text { Gumber } \\
\mathbf{( 5 0 )}\end{array}$ & $\mathbf{\%}$ & $\begin{array}{c}\text { Number } \\
\mathbf{( 5 0 )}\end{array}$ & $\mathbf{\%}$ & $\begin{array}{c}\text { Number } \\
\mathbf{( 5 0 )}\end{array}$ & $\mathbf{\%}$ \\
\hline$<25$ & 4 & 8 & 40 & 80 & 44 & 44 \\
\hline $25-29$ & 12 & 24 & 8 & 16 & 20 & 20 \\
\hline$\geq 30$ & 34 & 68 & 2 & 4 & 36 & 36 \\
\hline Mean & 29.81 & 23.00 & \multicolumn{2}{c|}{26.40} \\
\hline S.D & \multicolumn{3}{|c|}{3.76} & 3.39 & 4.94 \\
\hline \multicolumn{6}{|c|}{ Table 3. Distribution of GDM and Non-GDM Cases } \\
according to BMI
\end{tabular}

Table 3 shows that $68 \%$ women of GDM group had BMI $\geq$ $30 \mathrm{~kg} / \mathrm{m}^{2}$ showing a highly significant association ( $\mathrm{p}$ value 0.000 ) between obesity (BMI $\geq 30 \mathrm{~kg} / \mathrm{m}^{2}$ ) and GDM. Mean BMI was higher in women with GDM $\left(29.81 \pm 3.76 \mathrm{~kg} / \mathrm{m}^{2}\right)$ than Non-GDM $\left(23.00 \pm 3.39 \mathrm{~kg} / \mathrm{m}^{2}\right)$. The mean BMI of total patients was found out to be $\left(26.40 \pm 4.94 \mathrm{~kg} / \mathrm{m}^{2}\right)$.

\begin{tabular}{|c|c|c|c|c|c|}
\hline \multirow{2}{*}{$\begin{array}{c}\text { Maternal } \\
\text { Complications }\end{array}$} & \multicolumn{2}{|c|}{$\begin{array}{l}\text { GDM with } \\
\text { BMI } \geq 25\end{array}$} & \multicolumn{2}{|c|}{$\begin{array}{l}\text { GDM with } \\
\text { BMI < 25 }\end{array}$} & \multirow{2}{*}{$\begin{array}{c}P \\
\text { value }\end{array}$} \\
\hline & $\begin{array}{c}\text { Number } \\
(45)\end{array}$ & $\%$ & $\begin{array}{c}\text { Number } \\
\text { (5) }\end{array}$ & $\%$ & \\
\hline Polyhydramnios & 5 & 11.11 & 1 & 20 & 0.562 \\
\hline UTI & 10 & 22.22 & 1 & 20 & 0.909 \\
\hline Preterm Labour & 6 & 13.33 & 0 & 0 & 0.384 \\
\hline IUGR & 5 & 11.11 & 0 & 0 & 0.432 \\
\hline $\begin{array}{c}\text { Vaginal } \\
\text { Candidiasis }\end{array}$ & 4 & 8.88 & 2 & 40 & 0.042 \\
\hline
\end{tabular}

Table 4. Distribution of GDM Patients according to Maternal Complications in Relation to BMI

Table 4 suggests that maternal complications like UTI, preterm labour, IUGR are proportionately more in GDM with $\mathrm{BMI} \geq 25$ than GDM with $\mathrm{BMI}<25$. But in relation to BMI, polyhydramnios and vaginal candidiasis are proportionately more in GDM with BMI $<25$ than GDM with BMI $\geq 25$. Only vaginal candidiasis is found to be statistically significantly associated with BMI ( $\mathrm{p}$ value $<0.05$ ). 


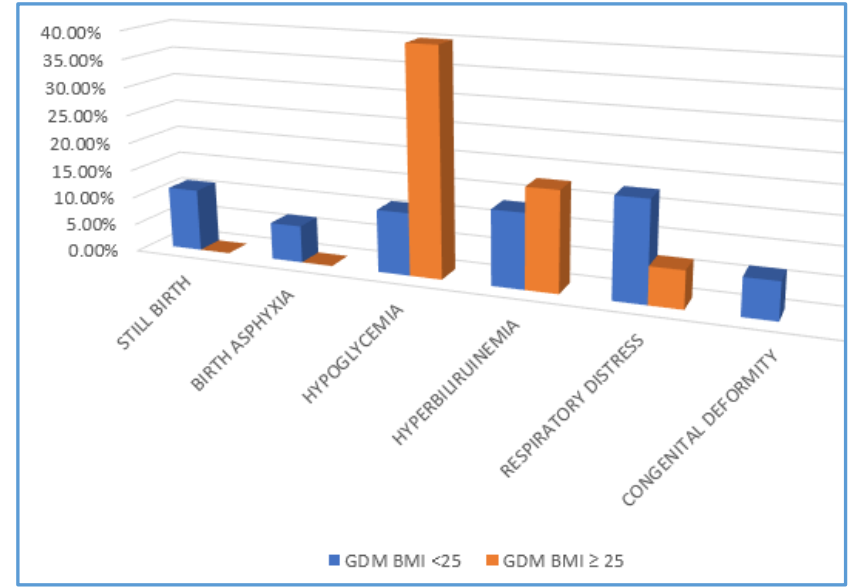

Figure 1. Distribution of GDM Patients according to Foetal Complications in Relation to BMI

Figure 1 illustrates that in GDM with BMI $\geq 25$ respiratory distress was occurring in $17.7 \%$ of cases followed by hyperbilirubinaemia in $13.33 \%$, and then still born and hypoglycaemia was occurring in the same number of patients followed by birth asphyxia and congenital deformity which accounts for lowest of GDM patients of BMI $\geq 25$.

\section{DISCUSSION}

GDM has been associated with neonatal morbidity and mortality including macrosomia, shoulder dystocia, other birth injuries and neonatal hypoglycaemia in addition to congenital anomalies and still births.(10,11) Further, the offspring are potentially at a higher risk of developing childhood obesity later in life.(12,13) Women with GDM have higher rates of caesarean deliveries and pregnancy-induced hypertension(14,15) and are at increased risk of future diabetes, predominantly type $2 \mathrm{DM}$ as are their children.(16) Thus, GDM offers an important opportunity for the development, testing and implementation of clinical strategies for diabetes prevention. ${ }^{(17)}$

In the present study maternal complications like UTI, polyhydramnios, IUGR and vaginal candidiasis are proportionately more in GDM group than in Non-GDM group. The study by Bhat et al (2010)(18) showed a $14.7 \%$ incidence of polyhydramnios in GDM vs. $2.7 \%$ in controls, which was quite similar to our study. Another study by Chanu et al (2015)(19)- the incidence of the same was $18.03 \%$ in GDM cases, which was slightly higher than our study. In a study conducted by Makwana M et al (2017),(20) the incidence of UTI in GDM vs. Non-GDM group were $28.95 \%$ vs. $2.51 \%$. Several studies have found out that the frequency of preterm labour is upto $20 \%$ higher in GDM pregnancies.(21) Also in a study conducted by Chanu et al (2015),(19) the same incidence was $16 \%$ which was quite similar to our study. The incidence of vaginal candidiasis was also higher in GDM than Non-GDM group, i.e. $15.79 \%$ vs. $5.25 \%$ the same study. Both findings were quite similar to our study. In a study conducted by Sudhansu SN et al (2014)(21) the incidence of vaginal candidiasis, polyhydramnios and preterm labour were $23 \%$, $8 \%$ and $4 \%$ in GDM cases respectively, whereas in our study it was $12 \%$ for all in GDM cases.

Neonatal complications like hyperbilirubinaemia, hypoglycaemia, respiratory distress, polycythaemia, hypocalcaemia were proportionately more in GDM group than in Non-GDM group. Hyperbilirubinaemia cases were found to be statistically significantly associated with GDM ( $p$ value < 0.05). Opara et al (2010)(22) found hypoglycaemia in $63.8 \%$ of babies born to mothers with diabetes, whereas in the present study it is only $15.5 \%$. Opara et al (2010)(22) found neonatal hyperbilirubinaemia in $57.4 \%$ of cases in contrast to the present study, where only $6(13.3 \%)$ babies born to GDM mother had jaundice. In a study by Pikee Saxena et al (2011),(23) biochemical and metabolic assessment revealed that hypocalcaemia (14\%), hyperbilirubinaemia $(34 \%)$ and polycythaemia (8\%) were significantly higher in neonates born to diabetic mothers. Kalyani KR et al (2014)(24) found that $21.2 \%$ of women with GDM had their babies with RDS as against $9.4 \%$ in the Non-GDM group, whereas in our study $17.7 \%$ of GDM had RDS as against $10.4 \%$ of Non-GDM group which is almost similar.

Mean BMI was higher in women with GDM $(29.81 \pm 3.76$ $\left.\mathrm{kg} / \mathrm{m}^{2}\right)$ than Non-GDM $\left(23.00 \pm 3.39 \mathrm{~kg} / \mathrm{m}^{2}\right)$. Nilofer AR et al (2012)(25) found obesity in $88.89 \%$ of GDM patients, whereas in our study $68 \%$ of GDM women were obese. In a study by Rajput R et al (2013),(26) a significant association was found between prevalence of GDM and increasing BMI of participants $(\mathrm{p}<0.001)$.

In our study maternal complications like UTI, preterm labour and IUGR are proportionately more in GDM with BMI $\geq 25$ than GDM with BMI $<25$. Frederick et al (2006)(27) found that every unit increase in pre-pregnancy BMI resulted in an $8 \%$ increased risk of pre-eclampsia. In our study IUGR occurs in $11.11 \%$ of GDM patients whose BMI $\geq 25$, which may result from developing pre-eclampsia.

Foetal complications with GDM in relation to BMI is not statistically significant (P value $>0.05$ ). Sebire et al (2001)(28) found that maternal obesity was associated with a higher foetal death rate (odds ratio of 1.4 with a rate of 7 per 1000), which is similar to our study. In a study by Meher-un-nisa et al (2009),(29) perinatal mortality rate remained relatively high in the obese group (9-25/1000) as compared to the control group (3/1000).

\section{CONCLUSION}

The present study illustrates that many maternal and foetal complications are significantly more among GDM population compared to Non-GDM group. Women of GDM group had BMI $\geq 30 \mathrm{~kg} / \mathrm{m}^{2}$ showing a highly significant association ( $\mathrm{p}$ value= 0.000 ) between obesity (BMI $\geq 30 \mathrm{~kg} / \mathrm{m}^{2}$ ) and GDM. But good maternal and foetal outcome can be expected from early and meticulous prenatal and intranatal care.

Due to high prevalence of GDM in India, early universal screening is essential. Screening for glucose intolerance during the early weeks of pregnancy is beneficial, as this policy would help in identifying undiagnosed diabetes prior to conception and to render appropriate care.

\section{REFERENCES}

[1] Sheshiah V, Das AK, Balaji V, et al. Gestational diabetes mellitus - guidelines. J Assoc Physicians India 2006;54:622-8.

[2] Albert RE. Diabetes in pregnancy obstetrics and gynaecology. Clinics of North America: WB Saunders Company 1996;23(1):10. 
[3] Kjos SL, Buchanan TA. Gestational diabetes mellitus. N Engl J Med 1999;341(23):1749-56.

[4] Jovanovic L, Pettitt DJ. Gestational diabetes mellitus. JAMA 2001;286(20):2516-8.

[5] Ben Haroush A, Yogev Y, Hod M. Epidemiology of gestational diabetes mellitus and its association with Type 2 diabetes. Diabet Med 2004;21(2):103-13.

[6] Glueck C, Goldenberg N, Streicher P, et al. Metformin and gestational diabetes. Curr Diabet Rep 2003;3(4):303-12.

[7] Kim C, Newton K, Knopp RH. Gestational diabetes and the incidence of type 2 diabetes: a systematic review. Diabetes Care 2002;25(10):1862-8.

[8] American Diabetes Association. Gestational diabetes mellitus. Diabetes Care 2004;27(Suppl 1):S88-S90.

[9] Nesbitt TS, Gilbert WM, Herrchen B. Shoulder dystocia and associated risk factors with macrosomic infants born in California. Am J Obstet Gynecol 1998;179(2):476-80.

[10] Casey BM, Lucas MJ, McIntire DD, et al. Pregnancy outcomes in women with gestational diabetes compared with the general obstetric population. Obstet Gynecol 1997;90(6):869-73.

[11] Dang K, Homko C, Reece EA. Factors associated with fetal macrosomia in offspring of gestational diabetic women. J Matern Fetal Med 2000;9(2):114-7.

[12] HAPO Study Cooperative Research Group, Metzger BE, Lowe LP, et al. Hyperglycemia and adverse pregnancy outcomes. N Engl J Med 2008;358(19):1991-2002.

[13] Hillier TA, Pedula KL, Schmidt MM, et al. Childhood obesity and metabolic imprinting: the ongoing effects of maternal hyperglycemia. Diabetes Care 2007;30(9):2287-92.

[14] Naylor CD, Sermer M, Chen E, et al. Cesarean delivery in relation to birth weight and gestational glucose tolerance: pathophysiology or practice style? Toronto Trihospital Gestational Diabetes Investigators. JAMA 1996;275(15):1165-70.

[15] Yogev Y, Ben-Haroush A, Chen R, et al. Active induction management of labor for diabetic pregnancies at term; Mode of delivery and fetal outcome--a single center experience. Eur J Obstet Gynecol Reprod Biol 2004;114(2):166-70.

[16] Dornhorst A, Rossi M. Risk and prevention of type 2 diabetes in women with gestational diabetes. Diabetes Care 1998;21(Suppl 2):B43-9.

[17] Buchanan TA, Xiang A, Kjos SL, et al. What is gestational diabetes? Diabetes Care 2007;30(2):S10511.
[18] Bhat M, KNR, Sarma SP, et al. Determinants of gestational diabetes mellitus: a case control study in a district tertiary care hospital in south India. Int J Diabetes Dev Ctries 2010;30(2):91-6.

[19] Chanu MM, Syiemech AJ, Pradhan B, et al. Clinical study of fetomaternal outcome of gestational diabetes mellitus. IOSR Journal of Dental and Medical Sciences 2015;14(4),Ver. VII: p. 53-6.

[20] Makwana M, Bhimwal RK, Ram C, et al. Gestational diabetes mellitus with its maternal and foetal outcome: a clinical study. Int J Adv Med 2017;4(4):919-25.

[21] Nanda SS, Dash K, Misra S, Das S, et al. Screening of gestational diabetes mellitus with 75gm OGTT and its effects on Feto-maternal outcome. Scholars Journal of Applied Medical Sciences (SJAMS) 2014;2(1C):340-4.

[22] Opara PI, Jaja T, Onubogu UC. Morbidity and mortality amongst infants of diabetic mothers admitted into a special care baby unit in Port Harcourt, Nigeria. Ital J Pediatr 2010;36(1):77.

[23] Saxena P, Tyagi S, Prakash A, et al. Pregnancy outcome of women with gestational diabetes in a tertiary level hospital of north India. Indian J Community Med 2011;36(2):120-3. doi: 10.4103/0970-0218.84130

[24] Kalyani KR, Jajoo S, Hariharan C, et al. Prevalence of gestational diabetes mellitus, its associated risk factors and pregnancy outcomes at a rural setup in Central India. International Journal of Reproduction, Contraception, Obstetrics and Gynecology 2014;3(1):219-24.

[25] Nilofer AR, Raju VS, Dakshayini BR, et al. Screening in high risk group of gestational diabetes mellitus with its maternal and fetal outcomes. Indian J of Endocrinol Metab 2012;16(Suppl 1):S74-S8.

[26] Rajput R, Yadav Y, Nanada S, et al. Prevalence of gestational diabetes mellitus and associated risk factors at a tertiary care hospital in Haryana. Indian J Med Res 2013;137(4):728-33.

[27] Frederick IO, Rudra CB, Miller RS, et al. Adult weight change, weight cycling and pre-pregnancy obesity in relation to risk of preeclampsia. Epidemiology 2006;17(4):428-34.

[28] Sebire NJ, Jolly M, Harris JP, et al. Maternal obesity and pregnancy outcome: a study of 287,213 pregnancies in London. Int J Obes 2001;25(8):1175-82.

[29] Meher-un-nisa, Aslam M, Ahmed SR, et al. Impact of obesity on Feto-maternal outcome in pregnant Saudi females. International Journal of Health Sciences, Qassim University 2009;3(2):187-95. 